\title{
Perfuração de Luvas durante Cirurgias Ginecológicas
}

\author{
Glove Perforation during Gynecologic Surgeries
}

Eddie Fernando Candido Murta, Cléber Sérgio da Silva, Noeli Aparecida Faria Duarte Ferreira

\begin{abstract}
RESUM0
Objetivo: analisar a incidência de perfuração de luvas cirúrgicas durante atos operatórios ginecológicos.

Métodos: estudo prospectivo de 454 luvas usadas em 65 procedimentos utilizando-se o método de pressão de água.

Resultados: do total de 454 luvas examinadas, foram verificadas perfurações em 54 (1 1,9\%), sendo estatisticamente significativo o maior número de perfurações em comparação ao grupo controle, uma $(1,7 \%)$ em 60 analisadas $\left(p<0,05\right.$, teste do $\left.\chi^{2}\right)$. Das 65 cirurgias, em $29(44,6 \%)$ ocorreram perfurações. Com relação ao tipo de perfuração, 44 (81,5\%) foram simples e 10 $(18,5 \%)$ foram múltiplas (mais de uma perfuração em uma única luva), tendo predominio da mão esquerda com $49(72,1 \%)$ perfurações. Entre os membros da equipe, o maior indice de perfuração foi nas luvas dos cirurgiões com 28 ocorrências (41,1\%), seguido dos primeiros auxiliares e instrumentadores, com 15 (22,1\%) cada, e segundos auxiliares, com 10 (14,7\%). $O$ local da luva onde ocorreu o maior número de perfurações foi o dedo indicador, com 20 (29,5\%), seguido do polegar, com 14 (20,6\%). A cirurgia que apresentou o maior indice de perfuração foi a histerectomia total, com $50 \%$ dos casos.

Conclusões: a perfuração de luvas durante cirurgias ginecológicas é freqüente. A histerectomia total é a cirurgia que apresenta maior indice de perfuração. Entre os membros da equipe, o cirurgião é quem apresenta o maior indice. O dedo indicador é o local da luva que apresenta maior número de perfurações.
\end{abstract}

PALAVRAS-CHAVE: Acidentes ocupacionais. Cirurgias: complicações. Infecção hospitalar. Infecção puerperal.

\section{Introdução}

A importância do uso de luvas tem se tornado cada vez maior diante do risco de infecção a

Disciplina de Ginecologia e Obstetrícia da Faculdade de Medicina do Triângulo Mineiro.

Menção Honrosa do Prêmio FEBRASGO de Ginecologia/99 no $48^{\circ}$ Congresso de Ginecologia e Obstetrícia em Goiânia; novembro de 1999.

Correspondência: Eddie Fernando Candido Murta

Disciplina de Ginecologia e Obstetrícia da Faculdade de Medicina do Triângulo Mineiro

Av. Getúlio Guaritá, S/N - Abadia

38.025-440 - Uberaba - MG

FAX: (34) 333-8710

e-mail: eddiemurta@mednet.com.br

Apoio financeiro do Conselho Nacional de Desenvolvimento Científico e Tecnológico (CNPq). que o profissional de saúde está exposto, em especial o médico-cirurgião ${ }^{1,2}$. A luva funciona como uma barreira evitando prováveis infecções dos membros da equipe cirúrgica que entram em contato com o tecido e/ou fluidos do paciente, protegendo-os da prevalência crescente de alguns agentes infecciosos como o virus da hepatite $\mathrm{B}$ e da sindrome da imunodeficiência adquirida ${ }^{2,3}$, bem como protegendo também o paciente, uma vez que persistem, nas mãos dos membros da equipe cirúrgica, microorganismos da flora residual mesmo após cumprir as técnicas de escovação e luva química ${ }^{2,4}$.

Outro fator seria o aumento da população bacteriana durante o ato cirúrgico, representando maior risco durante procedimentos cirúrgicos prolongados $^{2}$. Durante as cirurgias, a barreira 
imposta pelas luvas pode-se romper e produzir uma solução de continuidade por onde podem passar microorganismos ${ }^{1}$; por isto, a importância da escovação das mãos no pré-operatório com antiséptico para manter sua ação durante o ato operatório ${ }^{5,6}$.

A perfuração das luvas cirúrgicas ocorre em percentual que varia de 3,8 a $56,8 \%$, dependendo do tipo de cirurgia e de reesterilização das luvas ${ }^{7-9}$. No entanto, há poucos trabalhos sobre a incidência de perfuração de luvas em procedimentos ginecológicos. Por isso, este estudo tem como objetivo analisar o indice de perfuração das luvas em cirurgias ginecológicas.

\section{Material e Métodos}

Foi desenvolvido um trabalho prospectivo, para o qual foram examinadas 454 luvas utilizadas em 65 procedimentos cirúrgicos ginecológicos no Hospital Escola da Faculdade de Medicina do Triângulo Mineiro, no período de 19 de março a 21 de agosto de 1998. A coleta das luvas era realizada ao término de cada cirurgia, sendo colocadas separadamente em sacos plásticos e identificadas de acordo com o seu respectivo usuário (cirurgião, $1^{\circ}$ e $2^{\circ}$ auxiliares, instrumentador). Posteriormente eram testadas verificando-se a presença de perfurações e o local sendo a análise individual considerando-se o lado direito ou esquerdo, de acordo com o método descrito por Brough et al. ${ }^{10}$, que se baseia no enchimento de cada luva com água, amarrando-se o punho com barbante e espremendo-se o dorso, a palma, e após, cada dedo. Como grupo controle, foram utilizadas 60 luvas, colhidas do mesmo estoque, submetidas ao mesmo método de avaliação. Na análise estática utilizou-se o teste do $\chi^{2}$.

\section{Resultados}

Do total de 454 luvas examinadas, foram verificadas perfurações em 54 (11,9\%), sendo estatisticamente significativo o maior número de perfurações do grupo analisado em comparação com as do grupo controle, uma $(1,7 \%)$ em 60 , com $\mathrm{p}<0,05$ (teste do $\chi^{2}$ ). Das 65 cirurgias, 29 (44,6\%) tiveram perfurações. Com relação ao tipo de perfuração, 44 (81,5\%) foram simples e 10 (18,5\%) foram múltiplas (mais de uma perfuração em uma única luva). Entre os membros da equipe, o maior indice de perfuração foi nas luvas dos cirurgiões, com 28 ocorrências $(41,1 \%)$, seguido dos primei- ros auxiliares e instrumentadores, com 15 $(22,1 \%)$ cada, e os segundos auxiliares, com 10 $(14,7 \%)$. Na Tabela 1 está a distribuição do número de perfurações de luvas nos membros da equipe cirúrgica e por mão esquerda ou direita. Observa-se que a luva da mão esquerda teve o maior índice de perfuração, com 49 (72,1\%). O local da luva onde ocorreu o maior número de perfuração foi o dedo indicador, com 20 (29,5\%), seguido do polegar, com 14 (20,6\%) (Tabela 2). $\mathrm{Na}$ Tabela 3 estão indicadas as cirurgias que apresentaram maiores índices de perfuração.

Tabela 1 - Incidência de perfuração segundo a luva e a função na equipe cirúrgica.

\begin{tabular}{lrrrrrr}
\hline & \multicolumn{2}{c}{ Mão direita } & \multicolumn{2}{c}{ Mão esquerda } & \multicolumn{2}{c}{ Total } \\
& $\mathbf{n}$ & \multicolumn{1}{c}{$\%$} & \multicolumn{1}{c}{$\mathbf{n}$} & \multicolumn{1}{c}{$\%$} & $\mathbf{n}$ & $\%$ \\
\hline Cirurgião & 6 & 8,8 & 22 & 32,4 & 28 & 41,1 \\
$1^{\circ}$ Auxiliar & 6 & 8,8 & 9 & 13,2 & 15 & 22,1 \\
Instrumentador & 5 & 7,4 & 10 & 14,7 & 15 & 22,1 \\
$2^{\circ}$ Auxiliar & 2 & 2,9 & 8 & 11,8 & 10 & 14,7 \\
Total & 19 & 27,9 & 49 & 72,1 & 68 & 100 \\
\hline
\end{tabular}

Tabela 2 - Incidência de perfuração nos diferentes locais das luvas.

\begin{tabular}{lrrrrrr}
\hline & Mão direita & \multicolumn{2}{c}{ Mão esquerda } & \multicolumn{2}{c}{ Total } \\
& $\mathbf{n}$ & $\%$ & $\mathbf{n}$ & $\%$ & $\mathbf{n}$ & $\%$ \\
\hline Dedo indicador & 4 & 5,9 & 16 & 23,6 & 20 & 29,5 \\
Dedo polegar & 3 & 4,4 & 11 & 16,2 & 14 & 20,6 \\
Dedo anular & 5 & 7,4 & 7 & 10,3 & 12 & 17,5 \\
Dedo médio & 4 & 5,9 & 6 & 8,8 & 10 & 14,7 \\
Face dorsal & 2 & 2,9 & 3 & 4,4 & 5 & 7,4 \\
Face palmar & 1 & 1,4 & 4 & 5,9 & 5 & 7,4 \\
Dedo mínimo & 0 & 0 & 2 & 2,9 & 2 & 2,9 \\
Total & 19 & 27,9 & 49 & 72,1 & 68 & 100 \\
\hline
\end{tabular}

Tabela 3 - Freqüência de perfuração por cirurgia.

\begin{tabular}{lccccccr}
\hline & \multicolumn{2}{c}{ Mão direita } & \multicolumn{2}{c}{ Mão esquerda } & \multicolumn{2}{c}{ Total } \\
& $\mathbf{n}$ & $\%$ & $\mathbf{n}$ & $\%$ & $\mathbf{n}$ & $\%$ \\
\hline Histerectomia & 10 & 14,7 & 24 & 35,3 & 34 & 50,0 \\
$\begin{array}{l}\text { abdominal total }(\mathrm{n}=14) \\
\begin{array}{l}\text { Colpoperineoplastia } \\
(\mathrm{n}=8)\end{array}\end{array}$ & 6 & 8,8 & 11 & 16,2 & 17 & 25,0 \\
$\begin{array}{l}\text { Laparotomia } \\
\text { exploradora }(\mathrm{n}=7)\end{array}$ & 1 & 1,5 & 6 & 8,8 & 7 & 10,3 \\
$\begin{array}{l}\text { Outras cirurgias }(\mathrm{n}=9) \\
\text { Total }\end{array}$ & 2 & 2,9 & 8 & 11,8 & 10 & 4,7 \\
& 19 & 27,9 & 49 & 72,1 & 68 & 100
\end{tabular}




\section{Discussão}

A incidência de perfuração de luvas no nosso trabalho foi de $11,9 \%$ do total de 454 luvas, ocorridas em $29(44,6 \%)$ do total de 65 cirurgias. Os dados da literatura têm demonstrado índices variáveis de $3,8 \%$ a $56,8 \%{ }^{2,3}$, na dependência do tipo de cirurgia, reesterilização de luvas ou no uso de mais de uma luva.

Alguns autores demonstraram uma maior incidência de perfurações nas luvas da mão esquerda, sendo a parte mais afetada a do dedo indicador $^{11,12}$. Nossos achados são semelhantes aos destes autores, pois encontramos uma freqüência de 1,7 a 3,5 vezes maior no índice de perfuração da mão esquerda em relação à mão direita, nos diferentes membros da equipe. A mão esquerda é não-dominante na maioria dos seres humanos. Durante os atos cirúrgicos, geralmente é usada para afastar estruturas anatômicas para facilitar um melhor campo operatório. Por isto, explica-se a maior freqüência de perfurações na luva da mão esquerda. O dedo indicador foi o local mais freqüente de perfuração, com $29,5 \%$, seguido do polegar, com $20,6 \%$. Na literatura, o maior índice de perfuração é também no dedo indicador. Panduro-Barón et al. ${ }^{13}$ encontraram indice de $64,4 \%$ para o dedo indicador; entretanto, diferente do nosso resultado, o segundo local mais freqüente foi a palma da mão.

O horário em que se realiza a cirurgia parece influenciar na freqüência das perfurações de luvas. Panduro-Barón et al. ${ }^{13}$ encontraram uma relação estatisticamente significante entre a hora em que se realiza a cirurgia e o número de perfurações em 1052 pares de luvas utilizados em 258 cesáreas, sendo as perfurações mais freqüentes na madrugada, provavelmente correlacionando-se com o maior cansaço da equipe cirúrgica ${ }^{14}$. Bennett $\&$ Duff $^{15}$, estudando a freqüência de perfurações na utilização de duas luvas no total de 441 pares, demonstraram que nas luvas externas o índice de perfuração foi de $78 \%$, ao passo que nas luvas internas foi de $13 \%$. Estes autores concluíram que a utilização de duas luvas pode dar maior proteção aos membros da equipe cirúrgica na prevenção do contato direto com fluidos do organismo e sangue.

$\mathrm{O}$ uso de duas luvas pode dar maior proteção ao contato com os fluidos orgânicos e, conseqüentemente, minimizar o risco de aquisição de doenças infecto-contagiosas. Entretanto, o uso de duas luvas pode diminuir a habilidade, aumentar o desconforto e diminuir a sensibilidade do cirurgião Novak et al. ${ }^{16}$, estudando a sensibilidade das mãos com uso de uma ou duas lu- vas, demonstraram uma diminuição com o uso de duas luvas. Esta diminuição de sensibilidade seria devida a uma maior pressão sobre a pele da mão, que alteraria a sensibilidade tátil do cirurgião. Outros mecanismos de proteção seriam o uso de suturas mecânicas ou instrumentos que possam proteger o cirurgião das agulhas. Botet et al. ${ }^{17}$, estudando o uso de instrumento cirúrgico que protege a mão do cirurgião e as vísceras dos pacientes, demonstraram que a freqüência de perfuração de luvas nos casos em que se usou este instrumento é estatisticamente menor do que nos casos em que não se utilizou.

Concluimos que a histerectomia abdominal total é a cirurgia que apresenta maior indice de perfuração. A luva do cirurgião e, principalmente, a da mão esquerda é a que apresenta maior incidência. $\mathrm{O}$ índice de perfuração de luvas durante cirurgias ginecológicas deste trabalho pode ser considerado alto em comparação com os dados da literatura. Portanto, é necessário pesquisar mecanismos para uma melhor manutenção da barreira médico/paciente, como por exemplo, o reforço da borracha das luvas nos lugares de maior perfuração e na mão não-dominante ou o uso de instrumentos cirúrgicos que facilitam a sutura durante o ato operatório.

\section{SUMMARY}

Purpose: to analyze the frequency of glove perforation during gynecologic surgeries.

Methods: a prospective study of 454 gloves used in 65 surgeries by the water pressure method.

Results: of a total of 454 gloves, 54 (11.9\%) had perforations. Comparison with the control group showed $p<0.05$ ( $\chi^{2}$ test), 1 (1.7\%) perforation in 60 gloves tested. Of the total of gloves used in 65 surgeries, $29(44.6 \%)$ had perforations, $44(81 \%)$ had one perforation and $10(19 \%)$ had more than one perforation. The two most common sites of perforations were the index finger, 20 (29.5\%) and the thumb, 14 $(25.9 \%)$. Perforation was predominant in the left hand (72.1\%). The surgeons were the members of the team with the greatest number of glove perforations. Total hysterectomy was the most frequent surgery in which glove perforations occurred (50\% of the cases).

Conclusion: the glove perforations occurred with relatively high frequency during gynecologic surgeries. The index finger of the left hand proved to be the most affected region. Among the members of the team, the highest percentage of glove perforations occurred in those of the surgeons. Total hysterectomy had the highest perforation rate.

KEY WORDS: Glove perforation. Gynecologic surgery. 


\section{Referências}

1. Cole WR, Bernard H. Inadequacies of present methods of surgical skin preparation. Arch Surg 1964; 89:215-22.

2. Pinot AWH, Melo JFS, Muller AC, Dall'Onder S. Frequência de perfurações das luvas protetoras durante diferentes procedimentos cirúrgicos. Rev Ci AMECS 1996; 5:27-31.

3. Silva CAJ, Souza MS, Takimoto NR. Incidência de perfurações de luvas durante o ato operatório. ACM Arq Catarin Med 1992; 21:117-9.

4. Salas ID, Valencia MC, Ruiz FG, Silva CA, Ruiz JG. Rotura de guantes quirúrgicos en un hospital general. Rev Med Chile 1990; 118:44-8.

5. Goldenberg IS, Haley ID, Higashi GI. An evaluation of an iodine preoperative scrub detergent. Surg Gynecol Obstet 1962; 114:329-32.

6. Sebben JE. Surgical antiseptics. J Am Acad Dermatol 1983; 9:759-65.

7. Cruse PJ, Foord R. The epidemiology of wound infection. A 10-year prospective study of 62.939 wounds. Surg Clin North Am 1980; 60:27-40.

8. Dodds RD, Guy PJ, Peacock AM, Duffy SR, Barker $\mathrm{SG}$, Tomas MH. Surgical glove perforation. Br J Surg 1988; 75:966-8.
9. Penikett EJK, Gorrill RN. The integrity of surgical gloves tested during use. Lancet 1958; 2:10423.

10. Brough SJ, Hunt TM, Barrie WW. Surgical glove perforations. Br J Surg. 1988; 75:317.

11. Cohn GM, Seifer DB. Blood exposure in single versus double gloving during pelvic surgery. Am J Obstet Gynecol 1990; 162:715-7.

12. Hammer AJ. Surgical glove perfuration. Br J Surg 1989; 76:206-7.

13. Panduro-Barón JG, Gamboa R, Gaxiola Castro R, Acevedo López JA. Perfuración de guantes quirúrgicos en cesárea. Ginecol Obstet Mex 1996; $64: 430-4$.

14. Chapman S, Duff P. Frequence of glove perforations and subsequent blood contact in association with selected obstetric surgical procedures. Am J Obstet Gynecol 1993; 168:1354-7.

15. Bennett B, Duff P. The effect of double gloving on frequency of glove perforations. Obstet Gynecol 1991; 78:1019-22.

16. Novak CB, Patterson JM, Mackinnon SE. Evaluation of hand sensibility with single and double latex gloves. Plast Reconstr Surg 1999; 103:128-31.

17. Botet X, Serra J, Padros R, et al. Efficacy of PdB in preventing intraoperative risk of infectious diseases. World J Surg 1998; 22:1092-7.

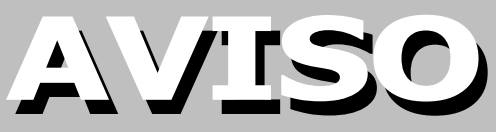

Comunicamos que a partir de abril, a FEBRASGO enviará aos sócios quites do corrente ano, o selo da FEBRASGO 2000.

\section{O Selo deverá ser colado no verso da carteira no local correspondente ao ano de 2000.}

Caso não tenha recebido sua carteira, entre em contato com a FEBRASGO o mais rápido possível. 